\title{
PENERAPAN MODEL PROJECT BASED LEARNING UNTUK MENINGKATKAN KREATIVITAS DAN KETERAMPILAN PROSES SAINS TENTANG SUHU DAN KALOR PADA SISWA KELAS V SDN 5 PANJER TAHUN AJARAN 2019/2020
}

\author{
Zauhjatun Solikhah', Rokhmaniyah², Kartika Chrysti Suryandari ${ }^{3}$ \\ Universitas Sebelas Maret \\ solikhahzauhjatun@gmail.com
}

\section{Article History}

accepted 01/10/2020

\begin{abstract}
The study aimed to describe the application of project based learning model and to improve the creativity and science process skills to fifth grade students of SDN 5 Panjer in academic year of 2019/2020. It was collaborative classroom action research (CAR) conducted in two cycles. The subjects were fifth grade students of SDN 5 Panjer in academic year of 2019/2020. Data collection techniques used observation, interview and test.The data validity used triangulation of techniques and triangulation of sources. Quantitative data analysis used descriptive statistics while qualitative data analysis included data reduction, data presentation, and drawing conclusion. The results showed that the application of project based learning model improved the creativity and science process skills to fifth grade students of SDN 5 Panjer in academic year of 2019/2020. The results of the student creativity were $70 \%$ in the first cycle and $80.1 \%$ in the second cycle. The results of science process skills were $77.4 \%$ in in the first cycle and $83.7 \%$ in the second cycle.
\end{abstract}

Keywords: project based learning, creativity, science process skills

\begin{abstract}
Abstrak : Penelitian ini bertujuan untuk mendeskripsikan penerapan model project based learning serta untuk meningkatkan kreativitas dan keterampilan proses sains. Penelitian ini merupakan penelitian tindakan kelas (PTK) kolaboratif yang dilaksanakan dalam dua siklus. Subjek penelitian ini adalah siswa kelas VA SDN 5 Panjer tahun 2019/2020. Teknik pengumpulan data menggunakan observasi, wawancara dan tes. Validitas data menggunakan triangulasi teknik dan sumber. Analisis data kuantitatif menggunakan statistik deskriptif, sedangkan analisis data kualitatif meliputi reduksi data, penyajian data, dan penarikan kesimpulan. Hasil penelitian ini menunjukkan bahwa model project based learning dapat meningkatkan kreativitas dan keterampilan proses sains pada siswa kelas VA SDN 5 Panjer tahun 2019/2020. Hasil kreativitas siswa siklus I sebesar 70\% dan siklus II sebesar $80,1 \%$. Hasil keterampilan proses sains siklus I sebesar $77,4 \%$ dan siklus II sebesar $83,7 \%$. Hal ini menunjukkan bahwa, model project based learning dapat meningkatkan kreativitas dan keterampilan proses sains pada siswa kelas VA SDN 5 Panjer tahun 2019/2020.
\end{abstract}

Kata kunci: Project based learning, Kreativitas, Keterampilan proses sains 


\section{PENDAHULUAN}

Kurikulum 2013 merupakan kurikulum yang membawa seorang guru untuk meningkatkan kualitas pembelajaran agar mampu memenuhi kebutuhan pembelajaran abad 21. Pembelajaran abad 21 diimplementasikan melalui kurikulum 2013 yang dikenal dengan keterampilan 4C yaitu : 1) critical thinking and problem solving, 2) creativity and innovation, 3) communication and, 4) collaboration. Keterampilan 4C tersebut perlu dikuasai melalui pembelajaran agar dapat diterapkan dalam kehidupan sehari-hari. Kurikulum 2013 menurut Minarta (2015: 380) merupakan kurikulum yang telah mengintegrasikan materi dari mata pelajaran ke dalam tema-tema, akan tetapi tidak kehilangan kompetensi dasar mata pelajaran yang ada khususnya pada pembelajaran di kelas 4,5 , dan 6 . Ilmu pengetahuan alam merupakan salah satu mata pelajaran wajib yang ada di sekolah dasar yang mempunyai peranan penting dalam kehidupan sehari-hari, karena IPA dapat melatih siswa untuk berfikir logis, rasional, kritis dan kreatif atau berpikir secara ilmiah.

Berkaitan dengan hal tersebut, proses pembelajaran IPA akan berjalan dengan baik ketika anak memiliki pengetahuan tentang konsep-konsep IPA yang akan dipelajari, serta keterampilan proses untuk memahami berbagai materi yang telah di sampaikan. Hakikat pembelajaran sains menurut Susanto (2016: 167) dapat diklasifikasikan menjadi tiga bagian yaitu : ilmu pengetahuan alam sebagai produk, proses, dan sikap. Pembelajaran dalam kurikulum 2013 juga menuntut siswa untuk berfikir kreatif dan dapat mengaplikasikannya. Kreativitas siswa perlu dikembangkan ketika proses pembelajaran tidak hanya kemampuan kognitifnya. Dalam proses pembelajaran interaksi guru dengan siswa harus seimbang agar tujuan pembelajaran dapat dicapai.

Oleh karena itu, pembelajaran IPA di SD seorang guru perlu memberikan model pembelajaran yang mampu memberikan siswa ketertarikan dan kesenangan siswa.. Pembelajaran dalam kurikulum 2013 juga menuntut siswa untuk berfikir kreatif dan dapat mengaplikasikannya. Kreativitas siswa perlu dikembangkan ketika proses pembelajaran tidak hanya kemampuan kognitifnya. Kemampuan untuk berkreativitas serta keterampilan dapat dikembangkan untuk tuntutan di masa depan. Menurut Duda, Susilo \& Newcombe, (2019: 1208) keterampilan proses penting dalam membantu peserta didik pada proses pembelajaran dengan adanya keterampilan proses sains ini siswa diberi kesempatan untuk mengembangkan kemampuan mereka.

Menurut Fathurrohman (2015: 124-125) langkah-langkah model pembelajaran project based learning terdapat 6 langkah, yaitu: (1) penentuan proyek, (2) perancangan langkah-langkah penyelesaian proyek, (3) penyusunan jadwal pelaksanaan proyek, (4) penyelesaian proyek dengan fasilitasi dan monitoring guru, (5) penyusunan laporan dan presentasi/publikasi hasil proyek, (6) evaluasi proses dan hasil proyek.Berdasarkan hasil observasi pembelajaran dan wawancara dengan guru kelas VA SDN 5 Panjer pada tanggal 25 November 2019 tentang kreativitas dan keterampilan siswa menggunakan model pembelajaran konvensional mendapatkan hasil bahwa (1) rendahnya rasa ingin tahu siswa, (2) belum maksimalnya keterampilan yang digunakan siswa dalam pembelajaran, (3) ide atau gagasan yang diberikan oleh siswa belum beragam, (4) belum dikembangkannya kreativitas siswa seperti pembuatan karya/produk dalam pembelajaran.

Berdasarkan hasil analisa guru kelas dan peneliti, hal tersebut disebabkan karena : (1) rendahnya keaktifan siswa dalam mengikuti pembelajaran, (2) rendahnya rasa ingin tahu siswa terhadap materi yang disampaikan guru, (3) metode pembelajaran yang digunakan oleh guru kurang melibatkan partisipasi siswa secara aktif, (4) pembelajaran yang membutuhkan praktik/eksperimen masih belum dilaksanakan secara maksimal.

Dari permasalahan yang muncul dan analisis penyebabnya, maka dapat disimpulkan bahwa pada pelaksanaan pembelajaran IPA di kelas VA SDN 5 Panjer 
memerlukan suatu metode pembelajaran yang mampu meningkatkan keterampilan kreativitas dan keterampilan proses sains sehingga tujuan pembelajaran dapat tercapai.

Adapun alternatif pemecahan masalah yang dianggap sesuai untuk mengatasi permasalahan tersebut adalah dengan menggunakan model pembelajaran project based learning. Fathurrohman (2015: 120) mengungkapkan bawa pembelajaran berbasis proyek merupakan model pembelajaran yang dilakukan secara sistematik mengikutsertakan peserta didik pembelajaran sikap, pengetahuan, dan keterampilan melalui investigasi dan perancangan produk. Sesuai dengan tujuan pembelajaran IPA yang tidak hanya menekankan pada aspek kognitif melainkan pada aspek keterampilan atau psikomotorik. Selain itu, Surya, Relmasira, dan Hardini (2018: 45) yang menyatakan bahwa model pembelajaran project based learning dapat membantu siswa menemukan konsep baru, pengalaman baru, serta dapat meningkatkan hasil belajar dan kreativitas siswa dalam memecahkan masalah maupun dalam pembuatan produk.

Berdasarkan latar belakang di atas maka peneliti tertarik untuk melakukan penelitian tindakan kelas yang bertujuan untuk : (1) mendeskripsikan penerapan model pembelajaran project based learning, (2) meningkatkan kreativitas siswa kelas V SDN 5 Panjer melalui penerapan model pembelajaran project based learning, (3) meningkatkan keterampilan proses sains siswa kelas V SDN 5 Panjer melalui penerapan model pembelajaran project based learning.

\section{METODE}

Penelitian ini merupakan penelitian tindakan kelas yang dilaksanakan secara kolaboratif antara peneliti dengan guru kelas. Subjek penelitian ini adalah seluruh siswa kelas VA SDN 5 Panjer tahun 2019/2020 yang terdiri dari 22 siswa yang terdiri dari 9 siswa laki-laki dan 13 siswa perempuan.

Penelitian ini dilaksanakan selama dua siklus dengan menerapkan model project based learning dengan langkah-langkah : (1) penentuan proyek, (2) perancangan langkah-langkah penyelesaian proyek, (3) penyusunan jadwal pelaksanaan proyek, (4) penyelesaian proyek dengan fasilitasi dan monitoring guru, (5) penyusunan laporan dan presentasi/publikasi hasil proyek, (6) evaluasi proses dan hasil proyek.

Langkah-langkah yang digunakan oleh peneliti mengacu dari pendapat yang dikemukakan oleh Fathurrohman (2015: 124-125), Sujiranto (2018: 93-96) \& Utami, Kristin \& Anugraheni (2018: 544) sehingga menghasilkan langkah-langkah seperti di atas.

Jenis data penelitian ini adalah data kualitatif berupa data tentang penerapan model project based learning, kreativitas dan keterampilan proses sains sedangkan data kuantitatif berupa data hasil tes keterampilan proses sains Teknik pengumpulan data menggunakan observasi, wawancara dan tes. Uji validitas data menggunakan triangulasi teknik dan sumber. Analisis data kuantitatif menggunakan statistik deskriptif, sedangkan analisis data kualitatif meliputi reduksi data, penyajian data, dan penarikan kesimpulan.

Aspek yang diukur dalam indikator kinerja penelitian ini adalah pelaksanaan langkah-langkah model project based learning, kreativas dan keterampilan proses sains setelah menerapkan model project based dengan persentase yang ditargetkan sebesar $80 \%$. Penelitian ini menggunakan prosedur penelitian yaitu terdiri dari tahap perencanaan, pelaksanaan, pengamatan, dan refleksi.

\section{HASIL DAN PEMBAHASAN}

Hasil pengamatan terhadap guru maupun siswa dalam penerapan model project based learning selalu mengalami peningkatan pada setiap siklus dan telah mencapai indikator pencapaian yang ditargetkan. 
Tabel 1. Persentase Hasil Pengamatan terhadap Guru dan Siswa pada Penerapan Model PbJL

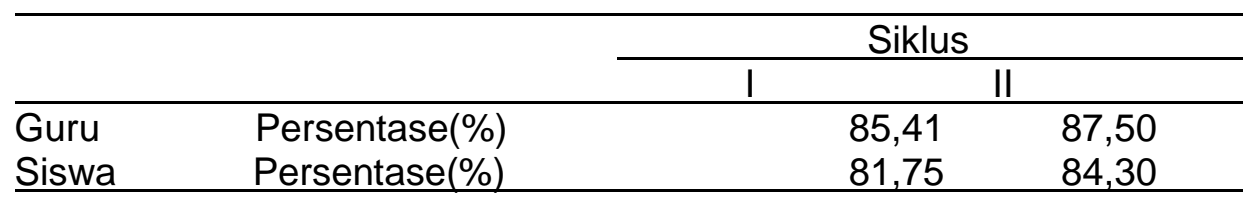

Berdasarkan tabel 1 di atas, dapat dilihat bahwa pembelajaran pada siklus I persentase rata-rata ketepatan guru dalam menerapkan langkah-langkah project based learning mencapai $85,41 \%$ dan siswa $81,75 \%$. Persentase tersebut telah memenuhi indikator kinerja penelitian, sehingga penelitian dilanjutkan ke siklus II dengan harapan pelaksanaan pembelajaran menggunakan model project based learning dapat meningkat pada siklus II. Pembelajaran siklus II dilaksanakan berdasarkan hasil refleksi siklus I agar pelaksanaan pembelajaran pada siklus II menjadi lebih baik. Hasil pelaksanaan siklus II mengalami peningkatan dari siklus I yaitu guru mencapai $81,75 \%$ dan siswa $84,30 \%$. Persentase tersebut telah memenuhi indikator kinerja penelitian, sehingga penelitian diakhiri pada pembelajaran siklus II.

Tabel 2. Hasil Kreativitas Siswa pada Penerapan Model PbJL

\begin{tabular}{llcl}
\hline & & \multicolumn{2}{c}{ Siklus } \\
\cline { 3 - 4 } & & I & II \\
\hline Siswa & Persentase(\%) & 70 & 80,1 \\
\hline
\end{tabular}

Berdasarkan tabel 2 di atas, dapat dilihat bahwa kreativitas siswa yang telah dilakukan pada siklus satu memperoleh persentase sebesar $70 \%$ dan siklus dua sebesar $80,1 \%$. Antara siklus satu dan siklus dua terjadi peningkatan sebesar $10,1 \%$. Pada siklus satu kreativitas siswa dalam kategori kreativitas sedang dan pada sklus dua meningkat menjadi kreativitas tinggi.

Tabel 3. Rata-Rata Observasi Keterampilan Proses Sains pada Penerapan Model PbJL

\begin{tabular}{lcc}
\hline \multicolumn{1}{c}{ Aspek } & \multicolumn{2}{c}{ Skor } \\
& KE1 & KE2 \\
Mengamati & 81,2 & 84,9 \\
Bertanya & 76,7 & 83,5 \\
Mengelompokkan & 80,5 & 82,8 \\
Menafsirkan & 70 & 83,5 \\
Mengkomunikasikan & & 83,9
\end{tabular}

78,9

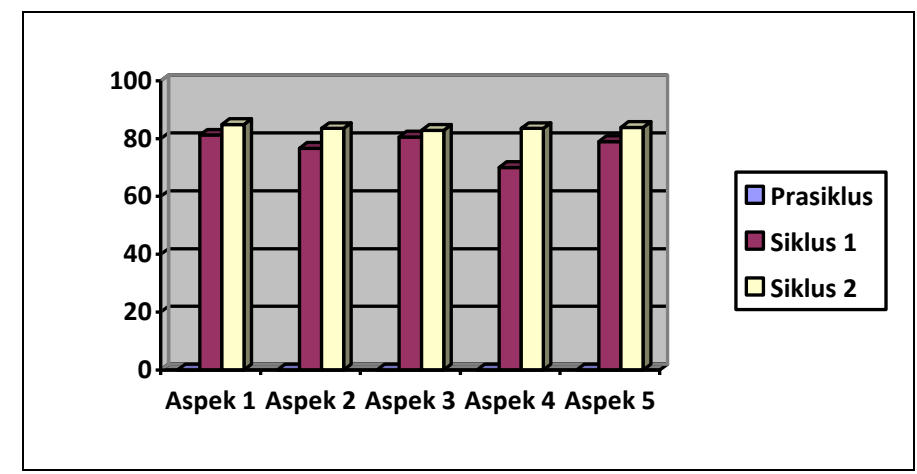




\section{Gambar 1. Hasil Observasi Keterampilan Proses Sains}

Berdasarkan tabel 3 di atas, pada siklus satu data yang didapatkan sebesar $77,4 \%$ dan siklus dua sebesar $83,7 \%$. Antara siklus satu dan siklus dua terjadi peningkatan sebesar $6,3 \%$. Selain diukur menggunakan lembar observasi, keterampilan proses sains siswa juga diukur menggunakan tes hasil kognitif tentang keterampilan proses.

Tabel 4. Hasil Tes Keterampilan Proses Sains

\begin{tabular}{llll} 
& & \multicolumn{2}{c}{ Siklus } \\
\hline & & I & II \\
\hline Siswa & Persentase(\%) & 54,5 & 77 \\
\hline
\end{tabular}

Berdasarkan tabel 4 di atas, hasil tes keterampilan proses sains pada siklus satu presentase yang didapatkan sebesar $54,5 \%$ dan siklus dua sebesar $77 \%$. Antara siklus satu dan siklus dua terjadi peningkatan sebesar $22,5 \%$.

Berdasarkan tabel 4 di atas, hasil tes kognitif keterampilan proses sains pada siklus satu presentase yang didapatkan sebesar $54,5 \%$ dan siklus dua sebesar $77 \%$. Antara siklus satu dan siklus dua terjadi peningkatan sebesar $22,5 \%$.

Model pembelajaran project based learning mampu menciptakan suasana pembelajaran yang mampu membawa siswa untuk menghubungkan ide-ide/gagasan dan keterampilan sehingga pada proses pembelajaran siswa tidak hanya pasif. Dengan adanya model pembelajaran juga mampu memberikan respon yang baik dari siswa dalam pembelajaran Hal ini sejalan dengan penelitian Tseng dan Chang (Fauzia, Diana \& Kusnadi, 2018: 66) yang menyatakan bahwa siswa yang belajar menggunakan model pembelajaran project based learning (PjbL) memiliki sikap yang lebih baik terkait sains dibandingkan siswa yang belajar dengan model pembelajaran langsung

Data tersebut di atas membuktikan pendapat Wena (Puspitasari, Amilda \& Nawawi, 2018: 26) secara umum bahwa model pembelajaran project based learning dapat membuat siswa mengalami proses pembelajaran yang bermakna, siswa membangun pengetahuannya di dalam konteks pengalamannya sendiri, dan dengan pengalaman belajar secara langsung, dapat mendukung untuk mengembangkan keterampilan. Selain itu, menurut Munakata dan Vaidya (2015: 48) menggunakan pembelajaran berbasis proyek mampu mampu mendorong proses kreatif dalam sains. Dengan adanya proyek dalam pembelajaran membuat siswa mampu untuk menghubungkan ide-ide, termotivasi, ingin tahu sehingga mendorong siswa untuk berkreativitas. Pembelajaran berbasis proyek menggunakan objek untuk membangkitkan rasa ingin tahu siswa dan juga mampu meningkatkan kemampuan siswa untuk berproduksi sebagai kultivasi kreativitas siswa ( Lou dkk, 2017: 2397).

Hasil penelitian diatas memperkuat penelitian sebelumnya yang dilakukan oleh Surya, Relmasira \& Hardini (2018) yang menyatakan bahwa model pembelajaran project based learning mampu meningkatkan hasil belajar dan kreativitas siswa kelas III SDN Sidorejo Lor 01 Salatiga Tahun ajaran 2018/2019. Penelitian sebelumnya juga dilakukan oleh Purwandari (2015) yang menyatakan bahwa melalui penerapan model pembelajaran berbasis proyek mampu meningkatkan keterampilan proses dan hasil belajar siswa kelas IV SDN 2 Srandakan.

\section{SIMPULAN}

Berdasarkan hasil penelitian yang diperoleh, maka dapat disimpulkan bahwa penggunaan model pembelajaran project based learning dengan langkah-langkah yang tepat dapat meningkatkan kreativitas dan keterampilan proses sains siswa. 
Berkaitan dengan hasil penelitian yang telah dicapai, peneliti mengajukan saran sebagai berikut : (1) bagi guru, hendaknya menjadi referensi untuk diterapkannya model pembelajaran yang sesuai dengan materi pembelajaran, (2) bagi siswa, hendaknya lebih percaya untuk menyampaikan pendapat, dan bertanya jika ada sesuatu hal yang belum dipahami (3) bagi sekolah, hendaknya menyediakan fasilitas, sarana, dan prasarana serta mendukung guru untuk berinovasi dalam menggunakan metode pembelajaran untuk meningkatkan kualitas pembelajaran, (4) bagi pembaca/peneliti lain, dapat menggunakan model project based learning yang sesuai dengan tuntutan perkembangan zaman.

\section{DAFTAR PUSTAKA}

Duda,H.J., Susilo,H. \& Newcombe,P. (2019). Enhancing Different Ethnicity Science Process Skill: Problem Based Learning through Practicum and Authentic Assesment. International Journal of Instruction, 12(1), 1207-1222.

Fathurrohman, M. (2015). Model-Model Pembelajaran Inovatif. Jogjakarta: Ar-Ruzz Media.

Fauzia, I,S., Diana, S., \& Kusnadi. (2018). Pengaruh Pembelajaran Berbasis Proyek dengan Portofolio terhadap Penguasaan Konsep Angoispermae dan Sikap Siswa SMA terhadap Sains. Indonesian Jurnal of BIOLOGY Education, 1 (2): 62-69.

Lou, dkk. (2017). A Study of Creativity in CaC2 Steamship-derived STEM Projectbased Learning. EURASIA Journal of Mathematics Science and Techonlogy Education. 13 (6) : 2387-2404.

Minarta, W. O. (2015). Pengaruh Teknik Pembelajaran POE (Predict, Observe, Explain) pada Metode Pembelajaran Kooperatif terhadap Hasil Belajar IPA Tema Pahlawanku Di Sekolah Dasar. Jurnal Penelitian Pendidikan Guru Sekolah Dasar, 3(2).

Munakata, M. \& Vaidya, A. (2015). Using Project-and Theme- Based Learning to Encourage Creativity in Science. Journal of College Science Teaching.

Purwandari, N. (2015). Peningkatan Keterampilan Proses dan Hasil Belajar IPA Melalui Penerapan Model Pembelajaran Berbasis Proyek Pada Siswa Kelas IV SDN 2 Srandakan. Jurnal Pendidikan Guru Sekolah Dasar Edisi 15 Tahun ke IV.

Puspitasari,M., Amilda, Nawawi,S. (2018). Pengaruh Model Pembelajaran Berbasis Proyek terhadap Keterampilan Proses Sains Siswa Kelas VII. Bioilmi Vol. 4 No. 1 Edisi Januari 2018.

Sujiranto. (2018). Model Pembelajaran Guru Abad 21. Bandung: Mujahid Press.

Surya, A.P., Relmasira,S.C., \& Hardini,A.T.A., (2018). Penerapan Model Pembelajaran Project Based Learning untuk Meningkatkan Hasil Belajar dan Kreatifitas Siswa Kelas III SD Negeri Sidorejo Lor 01 Salatiga. Jurnal Pesona Dasar Vol.6 No.1, April 2018 hal 41-54. ISSN 2337-9227. 
Volume 8 Nomor 3 Tahun 2020

Susanto,A. (2016). Teori Belajar dan Pembelajaran di Sekolah Dasar. Jakarta: Prenadamedia Group.

Utami,T., Kristin,F., \& Anugraheni,I. (2018). Penerapan Model Pembelajaran Project Based Learning (PjBL) Untuk Meningkatkan Kreativitas dan Hasil Belajar IPA Siswa Kelas 3 SD. Jurnal Mitra Pendidikan Vol 2 No 6 Juni (2018) 541-552. 